\title{
LC-GM²: Low-Cost Global Mobility Management Scheme in Proxy Mobile IPv6 Networks
}

\author{
Jongyoun $\mathrm{Kim}^{+} \cdot$ Jongsun Park $^{++} \cdot$ Jongpil Jeong ${ }^{+++}$
}

\begin{abstract}
This paper specifies a low-cost global mobility management architecture and protocol procedure called $\mathrm{LC}^{-\mathrm{GM}^{2}}$, which is based on Proxy Mobile IPv6. In LC-GM${ }^{2}$, mobility management is performed by the network entity. The benefit is the elimination of the wireless link data delivery tunnel overhead between a mobile node and the access router. To compare with the well-known Hierarchical Mobile IPv6 mobility management protocol and GPMIP, the location update, packet delivery, and total cost functions generated by a mobile node during its average domain residence time are formulated for each protocol based on Fluid-flow mobility model. Then, the impacts of various system parameters on the cost functions are analyzed. The analytical results indicate that the proposed global mobility management protocol can guarantee lower total costs.
\end{abstract}

Keywords: Global Mobility Management, Proxy Mobile IPv6, Hierarchical Mobile IPv6, Fluid-flow Mobility Model, Cost Function

\section{프록시 모바일 IPv6 네트워크에서 저비용의 글로벌 이동성관리 기법}

\author{
김 종 연 $^{\dagger} \cdot$ 박 종 선 ${ }^{+\dagger} \cdot$ 정 종 필 ${ }^{\dagger+}$
}

\begin{abstract}
요 약
본 논문에서는 PMIPv6를 기반으로 하는 $\mathrm{LC}-\mathrm{GM}^{2}$ 라는 저비용의 글로벌 이동성관리 아키텍처와 프로토콜 절차를 제안한다. $\mathrm{LC}-\mathrm{GM}^{2}$ 의 구성 은 여러PMIPv6 의 로컬 도메인과 계층적 구조로 코어 네트워크로 연결되어 있다. $\mathrm{LC}-\mathrm{GM}^{2}$ 에서 이동성 관리는 도메인 내에서의 모바일 노드 $(\mathrm{MN})$ 의 이동은 PMIPv6의 이동성관리 방법으로 수행되며 도메인간으로 이동할 때는 홈 네트워크 모바일 액세스 게이트웨이(MAG)가 이동 네 트워크의 지역 모바일 앵커(LMA)에 직접 프록시 바인딩 업데이트(PBU)를 수행하여 코어 네트워크(CN)의 게이트웨이를 통한 패킷 전송을 수 행하는 네트워크 엔티티 관점으로 수행된다. 분석 모델로 유체 흐름 이동성 모델을 기반으로 위치 업데이트 비용, 패킷 전달 및 총 비용 함수 의 다양한 시스템 매개변수의 영향 이용하여 계층적 모바일 IPv6(HMIPv6) 이동성관리 프로토콜과 GPMIP 아키텍처와 비교·분석한다. 수학적 분석의 결과는 다른 글로벌 이동성관리 기법들 간의 비용 분석의 결과를 통하여 제안된 글로벌 이동성관리 기법 $\left(\mathrm{LC}^{-} \mathrm{GM}^{2}\right)$ 이 전체적인 비용측 면에서 상당히 우수하다는 것을 보여준다.
\end{abstract}

키워드 : 글로벌 이동성관리, 프록시 모바일 IPv6, 계층적 모바일 IPv6, Fluid-flow 이동성 모델, 비용 함수

\section{1. 서 론}

모바일 IPv6(MIPv6)는 핸드오버를 수행하는 동안 인터넷 에 접속 유지를 가능하게 한다[1]. 상대노드 $(\mathrm{CN})$ 과 홈 에이

※ 이 논문은 2011년도 정부(교육과학기술부)의 재원으로 한국연구재단의 기초 연구사업 지원을 받아 수행된 것임(2011-0027030).

† 준 회 원 : 성균관대학교 컴퓨터공학과 석사

†† 준 회 원: 성균관대학교 정보통신공학과 석사

††† 정 회 원: 성균관대학교 산학협력단 산학협력중점교수

논문접수: 2012 년 6 월 1 일

수 정 일 : 1 차 2012년 7월 23일, 2 차 2012년 8월 6일, 3차 2012년 8월 16일 심사완료: 2012년 8월 18일

* Corresponding Author: Jongpil Jeong(jpjeong@skku.edu)
전트 $(\mathrm{HA})$ 사이에서 이동노드 $(\mathrm{MN})$ 의 시그널링 패킷의 양을 줄이기 위해서 계층적 모바일 IPv6(HMIPv6) 프로토콜이 설 계되었다[2]. $\mathrm{HMIPv6}$ 는 $\mathrm{MIPv} 6$ 의 확장 기능으로써 도메인 간과 도메인 내의 이동성관리를 가능하도록 제안한 프로토 콜이다. 그러나 확장된 MIPv6 프로토콜 기반의 핸드오버 작동으로 주로 $\mathrm{MN}$ 중심으로 수행 되는 문제점을 가지고 있다.

$\mathrm{IETF}$ 에서는 $\mathrm{MN}$ 의 지역화된 이동성관리 지원이 필요없 는 네트워크 기반의 지역 이동성관리 프로토콜(NETLMM: Network-based Localized Mobility Management)을 제안했 
다[3, 4]. 프록시 기반 모바일 IPv6(PMIPv6)는 이동성 관련 한 시그널링의 유도없이 $\mathrm{MN}$ 에 대한 IP 이동성을 수행한다 [5]. 그리고 IETF의 NETLMM 워킹 그룹에서는 PMIPv6 프로토콜과 PMIPv6 환경에서의 IPv4 제공 방안에 대한 표 준화를 진행해왔다. PMIPv6프로토콜은 MIPv6에서 파생되 었지만 HMIPv6와는 엄연히 다르다. 그러나 PMIPv6 단점으 로는 같은 액세스 네트워크 안에서만 $\mathrm{MN}$ 에 대한 IP 연결 및 접근성을 제공을 한다는 것이다. 그래서, $\mathrm{MN}$ 이 다른 NETLMM 액세스 네트워크를 이용하기 위해서는 글로벌 이동성을 지원하는 프로토콜이 필요하다[6].

본 논문에서는 PMIPv6를 기반으로 글로벌 이동성관리 방법 및 프로토콜를 $\mathrm{LC}-\mathrm{GM}^{2}$ (Low-Cost Global Mobility Management Scheme in Proxy Mobile IPv6 Networks)라 고 명명하고, 설계를 설명한다. $\mathrm{LC}_{-} \mathrm{GM}^{2}$ 의 기능 중 하나는 이동성관리를 $\mathrm{MN}$ 을 대신해서 네트워크 엔터티가 수행을 한다. 또 다른 기능으로 $\mathrm{MN}$ 의 네트워크 주소를 $\mathrm{DHCP}$ 서버 를 이용한 Stateful 방식을 사용하지 않는다. 제안한 방식의 효율성을 평가하기 위해서 위치 업데이트와 패킷 전달 비용 을 네트워크 분석모델과 유체 흐름 이동성 모델을 이용하여 $\mathrm{HMIPv} 6, \mathrm{GPMIP}[8]$ 와 $\mathrm{LC}-\mathrm{GM}^{2}$ 를 도메인 내외 사이즈, $\mathrm{MN}$ 의 평균이동 속도, 첫번째-두번재 계층, 두번째 계층간, 두 번째-세번째 계층간의 홉 카운트 등 여러 매개변수를 이동 하여 비교한 결과 $\mathrm{LC}-\mathrm{GM}^{2}$ 에서 전체적인 비용 측면에서 더 우수한 성능을 가진다.

논문의 나머지 부분의 구성 내용은 다음과 같다. 2 장은 관련 연구에 대한 개요를 설명한다. 3 장은 $\mathrm{LC}-\mathrm{GM}^{2}$ 에 대한 아키텍처 및 작동 절차, 4장은 이동성 모델에 대한 위치 업 데이트 및 패킷 전달에 대한 $\mathrm{LC}-\mathrm{GM}^{2}, \mathrm{HMIPv} 6$ 와 GPMIP 에 대한 총 비용 함수 및 결과를 설명한다. 마지막으로 5장 는 결론을 나타낸다.

\section{2. 관련 연구}

2.1 HMIPV6 기반 글로벌 이동성관리 아키텍처

$\mathrm{MIPv6}$ 의 정의에 따르면 $\mathrm{MN}$ 는 다른 서브넷으로 이동할
때 세션 연속성을 유지하기 위해 $\mathrm{CN}$ 와 $\mathrm{HA}$ 에 대한 $\mathrm{BU}$ (Binding Update)를 수행한다. HMIPv6는 $\mathrm{MN}$ 의 이동성 을 지역적으로 관리함으로써 $\mathrm{MN}$ 의 핸드오버로 인한 시그 널링을 줄여주는 프로토콜이다. HMIPv6는 Fig. 1에서와 같 이 여러 액세스 네트워크와 코어 네트워크로 구성되며 액세 스 네트워크에는 MAP(Mobility Anchor Point)와 무선 인터 페이스를 가지는 $\mathrm{AR}$ (Access Router)를 구성요소를 도입하 였다. $\mathrm{MAP}$ 은 개념적으로 액세스 네트워크의 $\mathrm{HA}$ 로 동작하 며 MIPv6에 대한 변경을 최소로 하여 성능 향상을 가져온 다. 또한 MAP을 사용함으로써 동일한 MAP 영역 내에서의 $\mathrm{MN}$ 의 이동은 $\mathrm{CN}$ 이나 $\mathrm{HA}$ 에 숨겨진다[2].

$\mathrm{HMIPv6}$ 에서 $\mathrm{MN}$ 은 3가지 주소를 가진다. 홈 네트워크에 서 구성한 고유한 $\mathrm{HoA}$ (Home of Address)와 이동 $\mathrm{MN}$ 의 현 위치를 알려주는 $\mathrm{CoA}$ (Care of Address)를 가진다. 도메 인 레벨의 $\mathrm{CoA}$ 는 $\mathrm{MN}$ 이 $\mathrm{MAP}$ 의 프리픽스를 기반으로 생성 한 $\mathrm{CoA}$ 로써 $\mathrm{RCoA}$ (Regional Care-of Address)라고 한다. 링크 레벨의 $\mathrm{CoA}$ 는 $\mathrm{AR}$ 의 프리픽스를 기반으로 생성한 $\mathrm{CoA}$ 이며 $\mathrm{LCoA}(\mathrm{On}-$ link Care-of Address)라고 한다. MN는 생성한 $\mathrm{RCoA}$ 와 $\mathrm{LCoA}$ 를 $\mathrm{MAP}$ 에 등록하고 $\mathrm{RCoA}$ 을 자신의 $\mathrm{HA}$ 와 $\mathrm{CN}$ 에게 등록한다. $\mathrm{MAP}$ 는 $\mathrm{RCoA}$ 와 $\mathrm{LCoA}$ 간의 바인 딩 정보를 이용하여 데이터를 최종적으로 $\mathrm{MN}$ 에게 포워딩 시켜준다. 만약 $\mathrm{MN}$ 이 같은 도메인 내의 $\mathrm{AR}$ 간을 이동하였 다면, $\mathrm{MN}$ 는 $\mathrm{LCoA}$ 만을 생성하고 새로운 $\mathrm{RCoA}$ 는 생성하지 않는다. 그러므로 같은 도메인 내의 $\mathrm{AR}$ 간을 이동은 $\mathrm{MN}$ 와 $\mathrm{HA}, \mathrm{CN}$ 간의 시그널링을 줄여준다.

$\mathrm{MN}$ 은 $\mathrm{MAP}$ 가 관리하는 영역에 진입하면 $\mathrm{AR}$ 에서 주기적 으로 방송하는 RA(Router Adverisement) 메시지를 받는다. 이 브로드케스팅 메시지에는 $\mathrm{AR}$ 이 $\mathrm{MAP}$ 의 영역 내에 있음 을 알리는 MAP 옵션을 포함하고 있다. MAP 옵션이 포함된 $\mathrm{RA}$ 메시지를 받은 $\mathrm{MN}$ 은 $\mathrm{AR}$ 의 $\mathrm{CoA}$ 인 $\mathrm{LCoA}$ 와 $\mathrm{MAP}$ 의 $\mathrm{CoA}$ 인 $\mathrm{RCoA}$ 를 Stateless 주소 자동구성 방식으로 생성한다. $\mathrm{MN}$ 은 $\mathrm{LCoA}$ 와 $\mathrm{RCoA}$ 를 생성한 후, $\mathrm{MAP}$ 에 대하여 $\mathrm{LCoA}$ 를 소스 주소로, $\mathrm{MAP}$ 주소를 목적지 주소로 하여 $\mathrm{RCoA}$ 를 $\mathrm{HoA}$ 옵션 주소로 하여 LBU(Local Binding Update) 메시지 를 전송한다. $\mathrm{MAP}$ 은 $\mathrm{LCoA}$ 와 $\mathrm{RCoA}$ 를 바인딩하며 바인딩이 성공적인지 아닌지(실패했을 경우 적절한 실패 코드 정보를

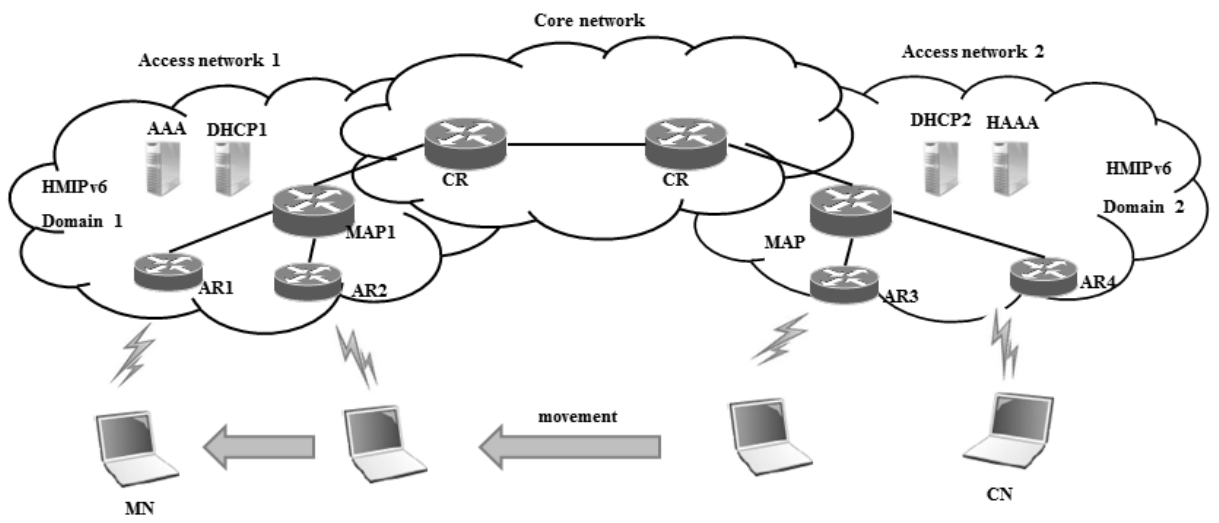

Fig. 1. HMIPv6 구조 
포함하는)를 가진 BAck(Binding Acknowledgement) 메시지 를 $\mathrm{MN}$ 으로 돌려준다. $\mathrm{LBU}$ 가 성공적으로 이루어지면 $\mathrm{MN}$ 은 $\mathrm{HA}$ 와 $\mathrm{CN}$ 에 대하여 $\mathrm{MIPv} 6$ 에서 규정된 $\mathrm{BU}$ 를 수행한다. 이 $\mathrm{BU}$ 메시지는 소스 주소를 $\mathrm{RCoA}$, 목적지 주소를 $\mathrm{HA} / \mathrm{CN}$ 의 주소로 하여 $\mathrm{HoA}$ 옵션에 $\mathrm{MN}$ 의 홈 주소를 담아서 $\mathrm{BU}$ 메시 지를 전송한다. 만일 $\mathrm{MN}$ 이 $\mathrm{MAP}$ 영역 내에서 다른 $\mathrm{AR}$ 로 이동하는 경우 $\mathrm{HA} / \mathrm{CN}$ 에 대해서는 동일한 $\mathrm{RCoA}$ 를 가지므 로 $\mathrm{BU}$ 을 필요로 하지 않으며 $\mathrm{LCoA}$ 를 갱신하는 $\mathrm{LBU}$ 만이 수행한다. 따라서 동일한 MAP 영역 내에서의 $\mathrm{MN}$ 의 이동은 $\mathrm{HA} / \mathrm{CN}$ 에 투명하게 이루어진다.

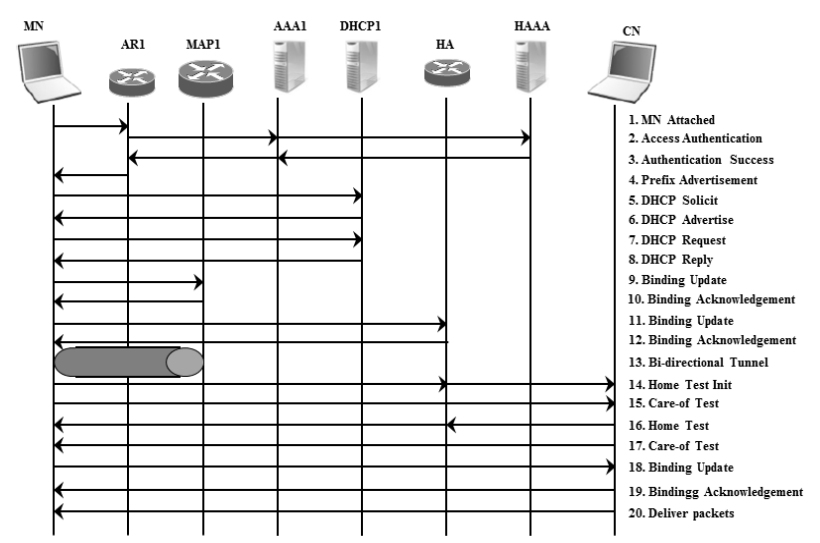

Fig. 2. HMIPv6 작동절차

1-4) $\mathrm{MN}$ 은 네트워크를 접근하여 $\mathrm{AR}$ 에서는 $\mathrm{AAA}$ 서버와 $\mathrm{HAAA}$ 서버를 거처 인증 프로파일을 받는다.

5-6) $\mathrm{MN}$ 은 $\mathrm{DHCP}$ 에 $\mathrm{MN}$ 의 프리픽스를 요청을 한다. 요 청 메시지에는 프리픽스 위임 옵션에 대한 신원 정보 확인 내용이 포함하여 $\mathrm{MN}$ 에 메시지를 보낸다.

7-8) $\mathrm{MN}$ 은 받은 메시지를 $\mathrm{DHCP}$ 서버에 프리픽스를 정 보를 업데이트한다.

9-10) $\mathrm{MN}$ 은 $\mathrm{MAP}$ 에게 바인딩 업데이트 요청한 후 응답 을 받는다.

11-12) HA에 바인딩 업데이트 요청한 후 응답을 받는다.

13) MAP와 터널링을 설정한다.

14-15) MN은 Home Test Init(HoTI) 메시지와 Care-of Test Init(CoTI) 메시지를 $\mathrm{CN}$ 에 전송한다.

16-17) $\mathrm{CN}$ 에서 각각에 대한 메시지를 처리하여 해당 메 시지에 대한 Keygen Token을 생성한 후에 Home Test(HoT)

메시지와 Care-of Test(CoT) 메시지를 $\mathrm{CN}$ 에 전송한다.

18-20) $\mathrm{MN}$ 은 $\mathrm{CN}$ 에 바인딩 업데이트 후 $\mathrm{MN}$ 과 $\mathrm{CN}$ 은 직 접적으로 통신을 한다.

2.2 PMIPv6 기반 글로벌 이동성관리 아키텍처

PMIPv6는 MIPv6 엔티티 개념을 재사용하는 네트워크 기 반 이동성관리 프로토콜이다[3]. PMIPv6 도메인은 PMIPv6 프로토콜을 사용하여 $\mathrm{MN}$ 의 이동성관리를 하는 도메인이다. PMIPv6 도메인의 구조는 Fig. 3에서 설명하고 있다.

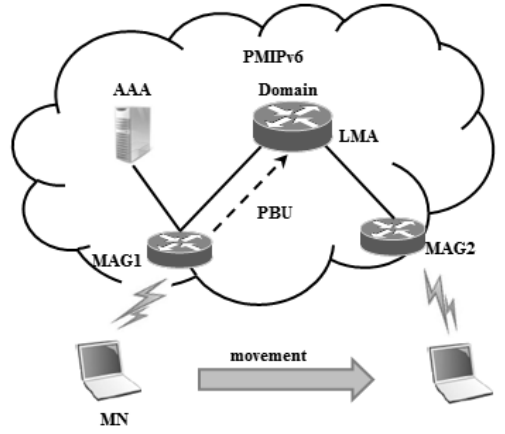

Fig. 3. PMIPv6 구조

PMIPv6 도메인 안에서 움직이는 $\mathrm{MN}$ 은 $\mathrm{NAI}$ (Network Access Identifier)와 같은 $\mathrm{MN}-\mathrm{ID}(\mathrm{MN}-$ Identifier)로 식별되 고, MN이 PMIPv6 도메인 안으로 들어가 접속 인증을 성공 적으로 수행하게 되면 $\mathrm{MN}$ 이 이동하여도 항상 홈 네트워크 에 있는 것처럼 만들어준다[4]. PMIPv6에서 MAG(Mobile Access Gateway)라고 불리는 새로운 기능 요소를 네트워크 에 요구하며, MAG는 $\mathrm{AR}$ 의 기능을 대체한다. 다른 기능 요 소로 PMIPv6에서는 LMA(Local Mobility Anchor)가 존재 한다. 도메인의 게이트웨이 위치에 배치되며 $\mathrm{MN}$ 의 주소에 대하여 전송을 책임지는 노드로 여러 $\mathrm{MAG}$ 들과 연관성을 지닌다. LMA는 자신이 관리하고 있는 $\mathrm{MN}$ 에게 $\mathrm{HNP}$ (Home Network Prefix)를 할당하여 전송하는 책임도 담당한다. $\mathrm{MN}$ 에게 할당되는 $\mathrm{HNP}$ 는 $\mathrm{LMA}$ 가 관리하는 네트워크 프리 픽스여야 한다. 이러한 패킷들은 이후 $\mathrm{MAG}$ 로 터널링을 통 하여 $\mathrm{MN}$ 로 전송한다. $\mathrm{MN}$ 이 도메인 외부로 보내는 모든 패 킷은 $\mathrm{MAG}$ 에서 터널링을 하여 $\mathrm{LMA}$ 로 전달하고 $\mathrm{LMA}$ 에서 터널을 벗겨 내어 외부로 전송한다.

$\mathrm{MN}$ 들은 LMA에 의하여 할당되는 $\mathrm{HNP}$ 를 통하여 자신의 주소를 Stateless 하게 구성하거나 DHCPv6를 이용하여 Stateful 하게 구성한다[5]. 이후 $\mathrm{MN}$ 은 같은 도메인 내의 여 러 MAG을 이동하여도 자신의 주소 변경 없이 움직일 수 있다. Fig 4는 PMIPv6의 절차를 설명한다.

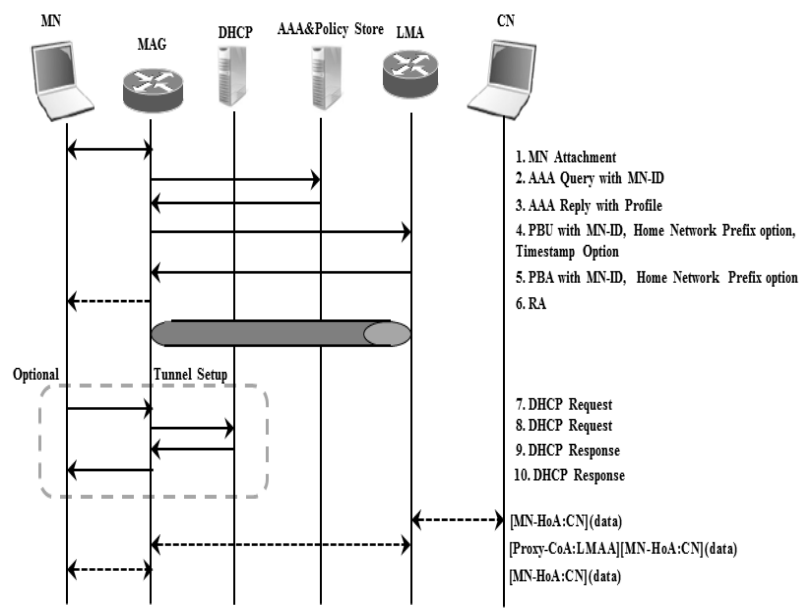

Fig. 4. PMIPv6 작동절차 


\subsection{GPMIP 아키텍처}

GPMIP[8]는 글로벌 이동성관리를 지원하기 위해 PMIPv6 확장한 구조이다. GPMIP는 코어 네트워크와 여러 액세스 네트워크로 구성하여 PMIPv6도메인에서의 다른 PMIPv6도메인으로 이동할 때 끓김없는 서비스를 지원한다. Fig. 5에서 GPMIP의 구조를 나타낸다.

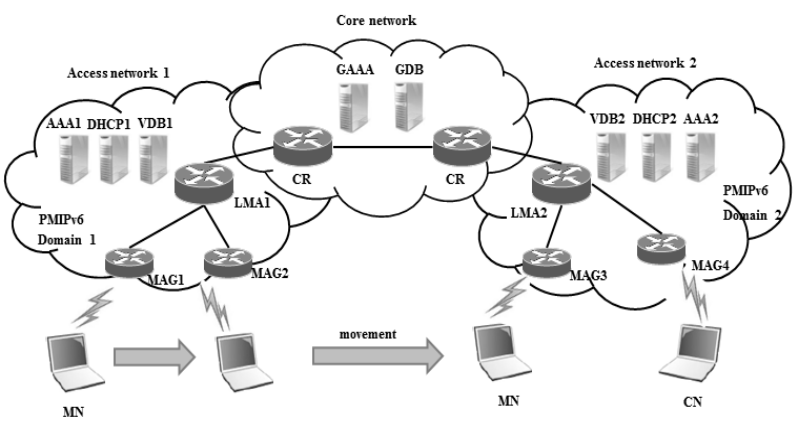

Fig. 5. GPMIP 구조

코어 네트워크에는 글로벌 위치 데이터베이스 서버 (GDB)와 글로벌 인증 권한 부여 및 계정 (GAAA) 서버로 구성된다. $\mathrm{GDB}$ 에는 최신 위치 정보를 저장하는 데 사용되 며 모든 $\mathrm{MN}$ 를 위한 위치 관리를 제어한다. GAAA 서버는 모든 $\mathrm{MN}$ 의 정책 프로필을 저장한다. 정책 프로필은 일반적 으로 같은 $\mathrm{MN}$ 의 $\mathrm{HNP}$, 허용 가능한 주소 구성 모드, 로밍 정책 및 네트워크 기반의 이동성 서비스를 제공에 필수적인 여러 매개변수 값들로 네트워크 기반 이동성 서비스 특성 및 기타 관련한 매개변수를 지니고 있다. 액세스 네트워크 는 PMIPv6 도메인으로 $\mathrm{DHCP}$ 서버, $\mathrm{AAAA}$ 서버 및 방문자 위치 데이터베이스(VDB)로 구성되어있다. PMIPv6 여러 도 메인들은 코어-라우터(CRS)에 의해 코어 네트워크에 연결 되어있다. GPMIP아키텍처에서 MN이 처음으로 PMIPv6 도 메인에 접속하면 $\mathrm{AAA}$ 서버는 $\mathrm{GAAA}$ 로 $\mathrm{AAA}$ 요청을 수행 한다. PMIPv6 도메인의 $\mathrm{AAA}$ 서버에는 해당 정책 프로필 을 가지고 있지 않는다. MAG는 GAAA로 액세스 인증 절 차를 거친 후 $\mathrm{GAAA}$ 서버에서 $\mathrm{MN}$ 의 정책 프로필을 얻을 수 있다. MAG는 $\mathrm{VDB}$ 서버에 위치 등록에 대한 업데이트 메시지를 보낸다. MN이 PMIPv6 도메인에 처음 들여온 경 우 $\mathrm{VDB}$ 서버에 추가를 요청하고 PMIPv6 도매인 안에서 $\mathrm{MAG}$ 핸드오버 발생시 업데이트를 요청을 하여 NAI와 $\mathrm{MN}-\mathrm{HoA}$ 사이의 관계를 구성하는 매핑 테이블 작성한다. $\mathrm{PMIPv6}$ 도메인에 $\mathrm{MN}$ 처음 들어온 경우 $\mathrm{VDB}$ 서버는 코어 네트워크의 GDB 서버에 위치 등록 또는 업데이트 메시지를 요청한다. $\mathrm{GDB}$ 서버에서는 $\mathrm{VDB}$ 서버에서 위치 업데이트 메시지를 수신하면 $\mathrm{MN}$ 의 매핑 테이블의 관련 항목을 업데 이트한다. GPMIP 아키텍처에서는 $\mathrm{DHCPv} 6$ 을 사용하여 Stateful 주소 구성을 하고, PMIPv6 액세스 링크 및 프리픽 스 할당에 사용한다. 하나의 도메인에는 여러 $\mathrm{MAG}$ 들과 $\mathrm{LMA}, \mathrm{VDB}, \mathrm{DHCP}$ 및 $\mathrm{AAA}$ 서버들과 보안 연결을 설정하 였다고 가정한다. 또한 PMIPv6 도메인에 있는 모든 $\mathrm{AAA}$
와 $\mathrm{VDB}, \mathrm{GAAA}$ 와 $\mathrm{GDB}$ 는 보안 연결을 설정했다고 가정한 다. Fig. 6은 GPMIP 아키텍처의 작동절차를 나타낸다.

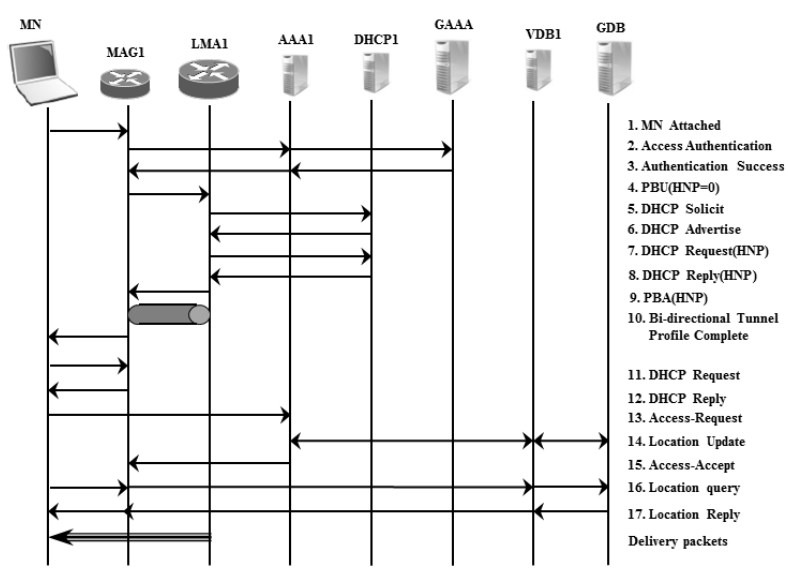

Fig. 6. GPMIP 작동절차

1-3) $\mathrm{MN}$ 는 $\mathrm{MAG}$ 로 부터 $\mathrm{AAA}$ 서버와 GAAA서버를 거 처 인증 프로파일을 받는다

4) $\mathrm{MAG}$ 는 $\mathrm{LMA}$ 에 $\mathrm{PBU}$ 를 보내고 $\mathrm{LMA}$ 는 $\mathrm{MN}$ 에 대한 프리픽스를 할당한다. $\mathrm{MN}$ 가 다른 액세스 링크로 이동하면 새로운 $\mathrm{MAG}$ 는 $\mathrm{MN}$ 의 $\mathrm{HNP}$ 를 습득하고, $\mathrm{MAG}$ 는 $\mathrm{NM}$ 의 $\mathrm{HNP}$ 를 $\mathrm{LMA}$ 에 프리픽스 할당을 요청한다.

5-8) $\mathrm{LMA}$ 는 $\mathrm{DHCP}$ 에 $\mathrm{MN}$ 의 프리픽스를 요청 후 $\mathrm{DHCP}$ 서버부터 받은 프리픽스를 업데이트한다.

9) LMA는 MAG에게 $\mathrm{PBA}$ 로 대답하고 $\mathrm{HNP}$ 매개 변수 를 설정한다.

10) LMA와 MAG의 양방향 터널이 설정되고 액세스 인 증 및 프로파일 획득이 완료된다.

11-12) $\mathrm{MN}$ 은 $\mathrm{MAG}$ 에 로컬 $\mathrm{DHCP}$ 프록시 주소를 요청 후 $\mathrm{DHCP}$ 응답 메시지와 프리픽스를 받아 $\mathrm{AAA}$ 서버에 액 세스를 요청한다.

14-15) AAA 서버는 DNS 업데이트를 수행한수 액세스 수락 메시지를 전송한다.

16-17) $\mathrm{MN}$ 이 $\mathrm{CN}$ 과의 통신을 원하면, $\mathrm{MN}$ 는 $\mathrm{VDB}$ 서버 에 $\mathrm{CN}$ 의 $\mathrm{NAI}$ 를 포함하여 위치 쿼리 메시지를 요청하여 $\mathrm{CN}$ 에 대한 위치 항목이 없으면 $\mathrm{VDB}$ 서버는 $\mathrm{GDB}$ 서버에 위치 쿼리 메시지를 전달하고 $\mathrm{GDB}$ 서버는 $\mathrm{CN}$ 의 주소를 반 환한다.

\section{3. 제안기법}

\section{$3.1 \mathrm{LC}-\mathrm{GM}^{2}$ 글로벌 이동성관리 아키텍처}

$\mathrm{LC}-\mathrm{GM}^{2}$ 은 글로벌 이동성관리를 제공 하기 위하여 PMIPv6 기반의 로컬 도메인과 코어 네트워크를 구성하였 다. HMIPv6와 GPMIP 아키텍처와 같은 계층적 구조 형태 이다. Fig. 7에 제안한 $\mathrm{LC}-\mathrm{GM}^{2}$ 의 네트워크 아키텍처를 소 개한다. 


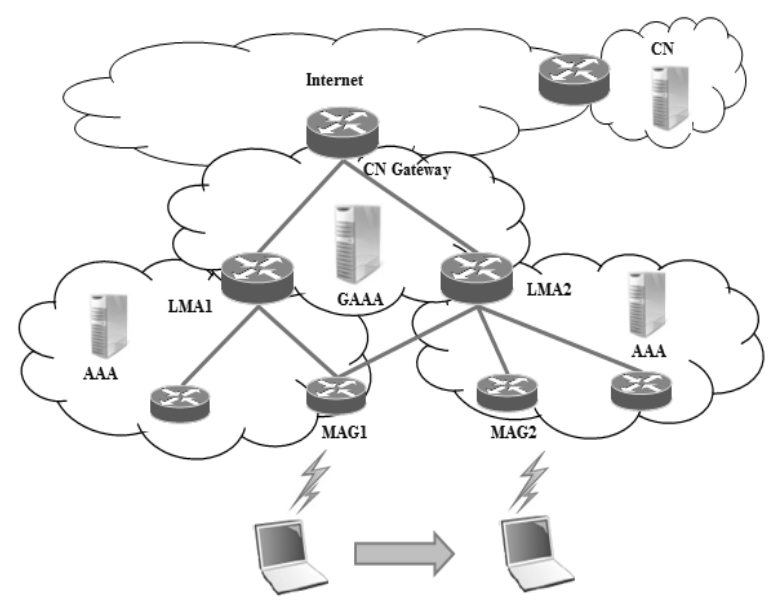

Fig. 7. LC-GM2 네트워크 아키텍처

$\mathrm{LC}-\mathrm{GM}^{2}$ 는 여러PMIPv6 의 로컬 도메인과 계층적 구조 로 코어 네트워크로 연결되어 있다. 로컬 도메인에는 MAG, $\mathrm{LMA}$ 와 로컬 도메인의 인증을 담당하는 $\mathrm{AAA}$ 서버로 구성 되어있다. 코어 네트워크에는 글로벌 인증 서버(GAAA) 서 버와 $\mathrm{CN}$ 으로 통하는 $\mathrm{CN}$ 의 게이트웨이로 구성되어 있다. 코 어 네트워크의 GAAA 서버의 역할은 다른 도메인으로 이동 할 때 로밍 정책 및 사용자 인증에 대한 수행을 하기 위해 서만 존재한다. GAAA는 관리 기관이 별도로 존재하여 다 른 도메인으로 이동할 때 인증에 대한 정보를 가지고 있다. 만약 이동한 도메인에 사용 권한이 없는 경우 LMA 버퍼에 저장되어 있던 패킷은 일정 시간이 지나면 자동으로 패킷을 폐기한다. 도메인 내에서의 $\mathrm{MN}$ 의 이동은 PMIPv6 도메인으 로 구성되어 있어 PMIPv6의 이동성관리 방법으로 수행된 다. $\mathrm{MN}$ 이 도메인간으로 이동할 때는 홈 네트워크 MAG가 이동 네트워크의 $\mathrm{LMA}$ 에 직접 $\mathrm{PBU}$ 를 수행하여 $\mathrm{CN}$ 의 게이 트웨이를 통한 패킷 전송을 수행한다. Fig. 8는 $\mathrm{MN}$ 이 이동 도메인의 $\mathrm{MAG}$ 에 접속하기 전에 패킷이 전송된 경우 처리 과정을 설명한다.

1) $\mathrm{MN}$ 이 이동할 경우 이동하는 $\mathrm{MAG}$ 의 브로드케스팅 메시지를 감지(L2 트리거)를 하여 홈 네트워크 내의 MAG 에 Location Report 메시지를 전달한다.

2) L2 트리거로 감지하여 이동 도메인의 LMA 주소를 포 함하는 Location Report를 홈 네트워크 내의 MAG로 전송 한다.

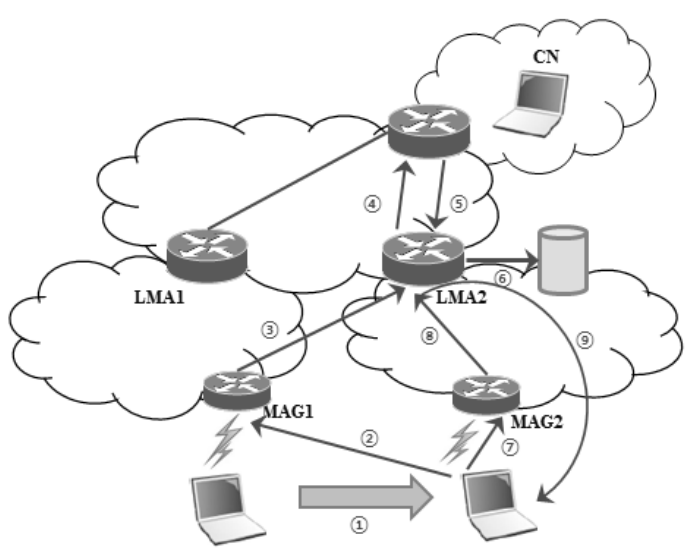

Fig. 8. 이동 도메인의 MAG에 접속하기 전에 패킷이 전송된 경우의 처리 과정

3) Location Report를 받은 홈 네트워크 MAG는 다른 도 메인으로 이동을 먼저 감지하여 이동 도메인의 LMA에 $\mathrm{PBU}$ 를 전송한다.

4-5) $\mathrm{PBU}$ 를 받은 이동 도메인의 LMA는 코어 네트워크 와 연결된 $\mathrm{CN}$ 의 게이트웨이에게 $\mathrm{BU}$ 를 요청한다. $\mathrm{CN}$ 의

게이트웨이는 $\mathrm{MN}$ 이 이동 도메인 내의 $\mathrm{MAG}$ 에 접속하기 전에 패킷이 들어오면 $\mathrm{BU}$ 테이블을 참고하여 이동

도메인의 LMA에 패킷을 전송한다.

6-9) $\mathrm{LMA}$ 는 패킷을 버퍼에 잠시 저장하였다가 $\mathrm{MN}$ 이 이동 도메인의 $\mathrm{MAG}$ 에 접속하여 $\mathrm{PBU}$ 를 $\mathrm{LMA}$ 에 전송할 때 저장되어 있던 패킷을 $\mathrm{MN}$ 에게 전송한다.

$\mathrm{CN}$ 의 게이트웨이에 바인딩 테이블은 이동 도메인의LMA 가 요청하면 $\mathrm{MN}$ 의 $\mathrm{HNP}$ 정보와 터널링 패킷 헤더를 테이블 에 삽입하고 제거하는 과정을 수행한다. $\mathrm{NM}$ 의 $\mathrm{HMP}$ 와 데 이터를 이동 도메인의 $\mathrm{MAG}$ 에게 전송하면 $\mathrm{MAG}$ 는 $\mathrm{LMA}$ 로 $\mathrm{PBU}$ 를 전송할 때 터널헤더를 추가한다. $\mathrm{LMA}$ 는 $\mathrm{CN}$ 의 게이트웨이에 바인딩 테이블에서 $\mathrm{MN}$ 의 $\mathrm{HNP}$ 에 대한 내용 을 삭제한다. Fig. 9은 $\mathrm{MN}$ 이 다른 도메인으로 이동할 때 터널을 통한 패킷 전송과정을 설명한다.

1) 데이터와 $\mathrm{HMP}($ Home Network Prefix, MN-ID) 를 $\mathrm{MAG}$ 에 전송한다.

2) $\mathrm{MAG}$ 는 $\mathrm{LMA}$ 에 터널 헤더를 추가하여 $\mathrm{LMA}$ 에 전송 한다.

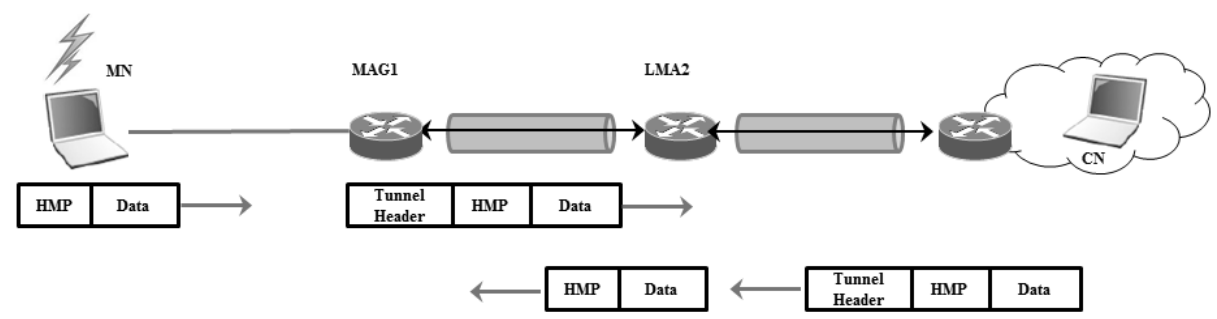

Fig. 9. MNO 다른 도메인으로 이동할 때 터널을 통한 패킷 전송 과정 
3) $\mathrm{CN}$ 에서 응답을 받은 $\mathrm{LMA}$ 는 $\mathrm{MAG}$ 에 터널 헤더를 사용하여 MAG에 데이터를 전송한다.

4) $\mathrm{MAG}$ 는 터널헤더를 제거하고 $\mathrm{NM}$ 에 데이터를 전송 한다.

$\mathrm{LC}-\mathrm{GM}^{2}$ 구조는 $\mathrm{GPMIP}$ 에서의 $\mathrm{DHCP}$ 와 $\mathrm{VDB}$ 를 사용하 지 않는다. $\mathrm{LMA}$ 에 의하여 할당되는 $\mathrm{HNP}$ 를 이용하여 $\mathrm{MN}$ 의 주소를 Stateless 하게 구성하는 방식을 사용하여 다른 도메인으로 이동할 때에도 주소를 변경하여 사용하지 않도 록 한다. $\mathrm{DHCP}$ 와 $\mathrm{VDB}$ 를 사용하지 않으므로 $\mathrm{GPMIP}$ 보다 노드의 홉을 줄일 수 있다. L2 트리거를 이용하여 직접 이 동 도메인의 $\mathrm{LMA}$ 에 $\mathrm{PBU}$ 를 전송하기 때문에 GPMIP에서 의 $\mathrm{VDB}$ 서버와 $\mathrm{DHCP}$ 서버를 필요로 하지 않는다. 그리고 $\mathrm{LTE}$ 망에서도 $\mathrm{DHCP}$ 에 대한 절차가 핸드오버 시 이루어지 고 있지 않다[16,17].

\subsection{LC-GM2 기반의 글로벌 이동성관리 작동절차}

도메인 내에서 PMIPv6 도메인으로 구성되어 있다. $\mathrm{MAG}$ 는 액세스 링크상에의 $\mathrm{MN}$ 이동을 모니터링 및 $\mathrm{LMA}$ 에 이동 관련한 시그널링 메시지를 전송한다. MAG는 $\mathrm{AAA}$ 서버에 $\mathrm{MN}$ 의 인증을 요청하고 인증의 결과값을 $\mathrm{GAAA}$ 에 업데이트를 요청한다. 이동한 도메인의 LMA는 $\mathrm{CN}$ 게이트웨이에게 이 후 들어오는 데이터에 대해서 이동 도메인의 $\mathrm{LMA}$ 로 전송을 하도록 $\mathrm{BU}$ 테이블에 등록을 요청 하는 $\mathrm{FBD}$ (Forced Bidirectional Communication) 를 전송한 다. $\mathrm{CN}$ 게이트웨이는 $\mathrm{FBD}$ 의 응답으로 $\mathrm{FBDA}$ (Forced Bidirectional Communication Acknowledgement) 를 전송한 다. Fig. 10은 도메인 내에서의 작동을 설명한다.

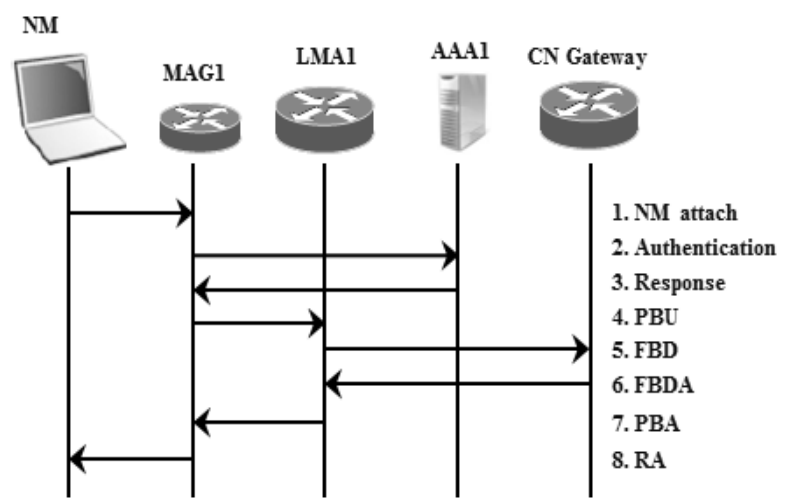

Fig. 10. LC-GM2 도메인 내에서의 작동절차

1-3) $\mathrm{MN}$ 가 $\mathrm{MAG}$ 를 통하여 $\mathrm{AAA}$ 서버에서 인증 절차를 수행한다.

4) 인증이 완료되면 LMA에 PBU를 요청한다.

5-6) $\mathrm{LMA}$ 는 코어 네트워크에 연결된 $\mathrm{CN}$ 의 게이트웨이 에 $\mathrm{FBD}$ 요청 후 응답을 받는다.

7) $\mathrm{LMA}$ 는 $\mathrm{MAG}$ 에게 $\mathrm{PBA}$ 를 전송한다.

8) $\mathrm{MAG}$ 는 $\mathrm{MN}$ 에게 $\mathrm{RA}$ 를 전송한다.
도메인간의 경우, $\mathrm{MN}$ 이 이동할 때 홈 네트워크 내의 $\mathrm{MAG}$ 는 다른 네트워크로 이동을 감지하고 이동하는 네트워 크의 $\mathrm{LMA}$ 에 직접 $\mathrm{PBU}$ 를 메시지를 전달한다. Fig. 11는 도 메인간에서의 작동절차를 설명한다.

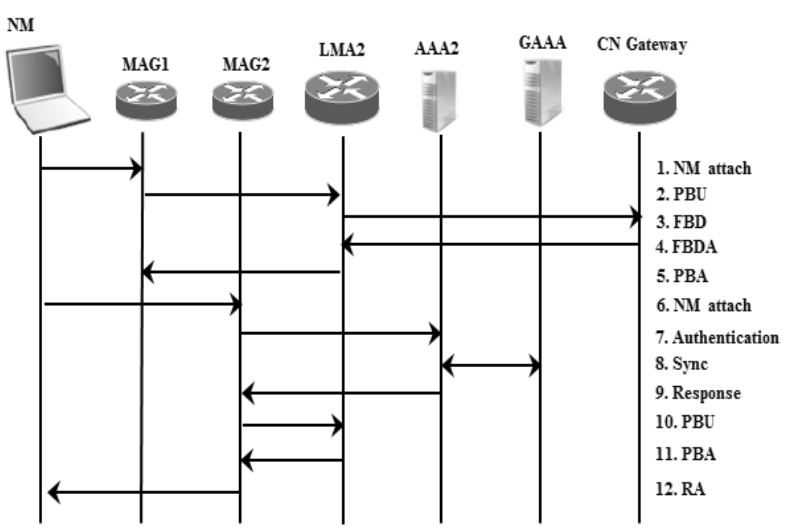

Fig. 11. LC-GM2 도메인간에서의 작동절차

1-2) $\mathrm{MN}$ 은 다른 도메인으로 이동할 경우 홈 네트워크 내의 $\mathrm{MAG}$ 는 이동하는 네트워크의 LMA2에 직접 $\mathrm{PBU}$ 메 시지를 전송한다.

3-4) LMA2는 코어 네트워크에 연결된 $\mathrm{CN}$ 의 게이트웨이 에 $\mathrm{FBD}$ 를 요청한 후 응답을 받는다.

5) LMA2는 MAG1에게 PBA를 전송한다.

6-9) $\mathrm{MN}$ 이 MAG2에 접속을 하여 MAG2는 $\mathrm{AAA} 2$ 서버 로 인증을 요청 후 응답을 받는다.

10-12) MAG2는 LMA2에게PBU를 전송하고 응답을 받아 $\mathrm{MN}$ 에게 RA를 전송한다.

\section{4. 성능 평가}

이 장에서는 네트워크 분석 및 $\mathrm{MN}$ 이동성 모델에 대한 위치 업데이트 및 패킷 전달에 대한 총 비용 함수를 설명한 다. 이러한 모델을 바탕으로, $\mathrm{HMIPv} 6, \mathrm{GPMIP}$ 와 $\mathrm{LG}^{-} \mathrm{CM}^{2}$ 에 대한 위치 업데이트비용, 패킷 전달비용, 평균 도메인 거 주 기간 동안 $\mathrm{MN}$ 에 의해 생성되는 총 비용 함수를 설명하 고 다양한 매개변수의 값을 변경하여 비교한다.

\section{1 분석 모델}

Fig. 12 과 같이 $\mathrm{LC}-\mathrm{GM}^{2}$ 는 계층적 네트워크 모델로 구성 되어 있다. 첫 번째 계층은 $\mathrm{CN}$ Gateway, GAAA서버로 구 성되며, 두 번째 계층에는 $\mathrm{LMA}, \mathrm{AAA}$ 서버로 구성되어 있 다. 세 번째 계층에는 MAG가 존재한다.

첫 번째 계층과 두 번째 계층의 홉 카운트는 $\mathrm{A}$ 이고, 두 번째 간의 홉 카운트는 $\mathrm{B}$ 이고, 두 번째와 세 번째 간의 홉 카운트는 $\mathrm{C}$ 이다. $\mathrm{MAG}$ 와 $\mathrm{AAA}$ 간의 홉 카운트는D이다. $\mathrm{D}$ 는 도메인 내에서 $\mathrm{MAG}$ 에서 $\mathrm{AAA}$ 서버, $\mathrm{VDB}$ 서버의 홉 카운 트를 의미한다. $\mathrm{MN}$ 과 $\mathrm{CN}$ 의 홉 카운트는 1 이다. $\mathrm{A}, \mathrm{B}, \mathrm{C}$, 


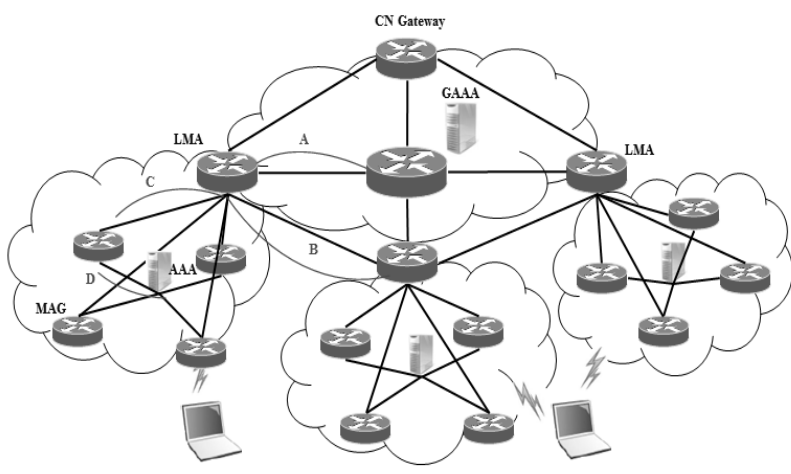

Fig. 12. 네트워크 분석모델

$\mathrm{D}$ 는 유선 링크이며 마지막 홉은 $\mathrm{MN}$ 은 무선 링크이다.

본 논문에서는 $\mathrm{LC}-\mathrm{GM}^{2}, \mathrm{HMIPv6}, \mathrm{GPMIP}$ 의 비용 분석을 위해 유체 흐름 이동성 모델[12-14]을 사용한다. 한 도메인 에는 동일한 서브넷 $\mathrm{N}$ 개를 구성한다고 가정한다. 모든 서브 넷은 원형으로 되어있으며 같은 크기이고 서로 붙어있다고 가정한다. 서브넷의 핸드오버는 모두 동일하다고 가정한다. $\mathrm{MN}$ 들이 평균 움직이는 속도를 $\mathrm{V}$ 로 가정하고, $\mathrm{MN}$ 의 운동 방향은 균일한 값 $[0,2 \pi]$ 로 제한한다. 그리고 서브넷의 영역 은 $s$ 라고 정의한다. $\mathrm{MN}$ 의 서브넷 체류 시간 $t_{s u b}$ 은 다음 수식으로 나타낸다[15].

$$
t_{\text {sub }}=\frac{\sqrt{\pi s}}{2 v}
$$

또한 도메인에 머물러있는 $\mathrm{MN}$ 의 서브넷의 개수 $i(0 \leq i \leq N)$ 로 정의한다. 외부에 도메인 머물러있는 상태를 $i \equiv 0$ 로 정의한다. $i \equiv N$ 은 모바일 노드가 도메인 밖으로 움 직이는 상태를 정의한다. $\Pi_{i}$ 는 평균 상태 확률을 의미한다.

$$
\pi_{i}=\left\{\begin{array}{ll}
\frac{1}{2} & \text { if } i \equiv 0 \\
\frac{1}{2}\left(\frac{1}{\sqrt{N}}\right)\left(1-\frac{1}{\sqrt{N}}\right) & \text { if } 1 \leq i \leq N-1 \\
\frac{1}{2}\left(1-\frac{1}{\sqrt{N}}\right)^{N-1} & \text { if } i \equiv N
\end{array}\right\}
$$

$\Phi(N)$ 은 $\mathrm{MN}$ 이 주어진 도메인에 방문한 평균 서브넷를 나 타낸다.

$$
\Phi(N) \equiv \sum_{i=1}^{N} i \pi_{i}
$$

마지막으로, $\mathrm{MN}$ 의 평균 도메인 체류시간 $t_{\text {domain }}$ 를 구한다.

$$
t_{\text {domain }}=t_{\text {sub }} \cdot \Phi(N)
$$

4.2 비용 분석

$L_{H M}, L_{H H}$ 와 $L_{H C}$ 는 $\mathrm{MN}$ 에서 $\mathrm{HAAA}$ 서버 와 $\mathrm{DHCP}$ 서버 의 위치 업데이트 비용, $\mathrm{NM}$ 에서 $\mathrm{HA}$ 의 위치 업데이트 비용 과 $\mathrm{CN}$ 의 위치 업데이트 비용을 나타낸다. $L_{H M I P}$ 는 평균 위 치 업데이트 비용을 나타낸다. Fig. 12의 네트워크 분석모델 을 사용하여 Fig. 2의 수행 절차에 따라 MAP이 $\mathrm{HA}$, $\mathrm{HAAA}$ 전송시 $a, \mathrm{AR}$ 이 $\mathrm{MAP}$ 에 전송시 $c, \mathrm{AR}$ 이 $\mathrm{AAA}$ 에 전송시 $d$ 를 나타낸다.

$$
L_{H M}=2(\theta+d \eta+(c+a) \eta)+4 c \eta+4 a \eta+2 c \eta=2 \theta+2(3(c+a)+d) \eta
$$

$$
L_{H H}=2 \theta+(4 d+2(c+a)) \eta
$$

$$
L_{H C}=2 \theta+2(d+c+a) \eta
$$

$$
L_{H M I P}=\pi_{0} \cdot\left(L_{H M}+L_{H H}+\varepsilon L_{H C}\right)+(\Phi(N)-1) \cdot L_{H M} \cdot \varepsilon L_{H C}
$$

$\pi_{0} \cdot\left(L_{G G}+\varepsilon L_{G C}\right)$ [12] 은 도메인간 비용이고 $(\Phi(N)-1)$ 는 도메 인 내 비용을 나타낸다. 하나의 패킷이 HA에서 인터셉트 없이 $\mathrm{MN}$ 에게 직접 전송되는 확률을 $q$ 라고 하고 $\mathrm{HA}$ 의 인 터셉트 없이 직접 패킷 전달에 의해 발생한 비용을 $D_{h d i r}$, $D_{\text {hindir }}$ 및 $D_{\text {HMIP }}$ 를 나타낸다.

$$
\begin{gathered}
D_{\text {hdir }}=2 \tau \theta+(2 \tau c+b) \eta \\
D_{\text {hindir }}=2 \tau \theta+\tau(2 c+b) \eta+(2 c+b) \eta \\
D_{H M I P}=\rho \cdot t_{\text {sub }} \cdot \Phi(N) \cdot\left\{q D_{\text {hdir }}+(1-q) D_{\text {hindir }}\right\} \\
C_{\text {HMIP }}=L_{H M I P}+D_{\text {HMIP }}
\end{gathered}
$$

$L_{G V}$ 는 $\mathrm{MN}$ 이 도메인에 접속할 때 GAAA 서버의 인증절 차와 $\mathrm{DHCP}$ 를 이용한 $\mathrm{HNP}$ 를 생성하는 과정의 위치업데이 트 비용을 나타내며, $L_{G C}$ 는 도메인 간 이동할 때 $\mathrm{GDB}$ 서버 까지의 비용을 설명한다. $L_{G G}$ 는 위치 업데이트 쿼리 비용 을 설명한다. $L_{G P M I P}$ 는 위치 업데이트 평균 비용을 설명한 다. Fig. 6의 작동절차로 $\mathrm{LMA}$ 가 $\mathrm{GAAA}, \mathrm{GDB}$ 전송시 $a$, $\mathrm{LMA}$ 간의 전송시 $b, \mathrm{MAP}$ 가 $\mathrm{LMA}$ 로 전송 시 $c, \mathrm{MAP}$ 가 $\mathrm{AAA}, \mathrm{VDB}$ 에 전송시 $d$ 를 나타낸다. GPMIP에 정의된 시 그널링 메시지는 서로 다른 크기의 패킷을 가지고 있지만 그것은 모드 같다고 가정한다. 따라서 위치 업데이트 비용 은 출발지와 목적지 사이의 링크 홉에 비례한다. $\theta$ 와 $\eta$ 은 각각 무선의 단위 전송 비용 및 유선 링크를 상징하고, $\tau$ 는 터널링 패킷의 추가 중량을 나타낸다. GPMIP에 정의된 시 그널링 메시지는 서로 다른 크기의 패킷을 가지고 있지만 동일하다고 가정한다. 
$L_{G G}=2 \theta+2 d \eta+2(c+a) \eta+2 c \eta+4 c \eta=2 \theta+2(d+3 c) \eta$

$L_{G V}=2 \theta+2 d \eta+2 d \eta+2(c+a) \eta=2 \theta+2(2 d+c+a) \eta$

$$
L_{G C}=2 \theta+(2 d+2(c+a)) \eta
$$

$$
L_{G P M I P}=\pi_{0} \cdot\left(L_{G G}+\varepsilon L_{G C}\right)+(\Phi(N)-1) \cdot L_{G V} \cdot \varepsilon L_{G C}
$$

$\mathrm{MN}$ 이 이동할 때 도메인 내외부의 $\mathrm{CN}$ 의 평균 수는 $\varepsilon$ 라 가정하고 $\pi_{0} \cdot\left(L_{G G}+\varepsilon L_{G C}\right)$ 는 도메인 내의 비용이고 $(\Phi(N)-1) \cdot L_{G V}$ 는 도메인간의 비용을 의미한다. $D_{G P M P}$ 는 GPMIP의 평균 패킷 전송 비용을 나타낸다.

$$
D_{G P M I P}=\rho \cdot t_{s u b} \cdot \Phi(N) \cdot(2 \theta+(2 \tau c+b) \eta)
$$

$C_{G P M I P}$ 는 GPMIP의 총 비용을 의미한다.

$$
C_{G P M I P}=L_{G P M I P}+D_{G P M I P}
$$

제안한 $\mathrm{LC}-\mathrm{GM}^{2}$ 의 네트워크 분석모델도 계층적 구조를 사용한다. 도메인 내에서 GPMIP와 동일한 PMIPv6을 로컬 도메인으로 사용한다. 하지만 $\mathrm{VBD}$ 와 $\mathrm{GDB}$ 를 사용하지 않는 다. $L_{G i n}$ 는 Fig. 10 의 도메인 내의 작동절차 기준으로 위치 업데이트 비용을 설명하며, $L_{\text {Gout }}$ 는 Fig. 11 의 도메인간에서 의 작동절차를 기준으로 $\mathrm{MN}$ 이 다른 도메인으로 이동할 때 위치 업데이트 비용을 설명한다. $L_{L C G M}$ 은 총 위치 업데이트 비용을 설명한다. LMA가 GAAA, GN 게이트웨이에 전송시 $a, \mathrm{LMA}$ 간의 전송시 $b, \mathrm{MAP}$ 가 $\mathrm{LMA}$ 로 전송 시 $c, \mathrm{MAP}$ 가 $\mathrm{AAA}$ 에 전송시 $d$ 를 나타낸다.

$$
\begin{gathered}
L_{\text {Gin }}=2 \theta+2(c+a+d) \eta \\
L_{\text {Gout }}=3 \theta+2(2 c+d+a) \eta \\
L_{L C G M}=\pi_{0}\left(\varepsilon L_{\text {Gin }}\right)+(\Phi(N)-1) \cdot L_{\text {Gout }}
\end{gathered}
$$

$D_{L C G M}$ 는 $\mathrm{LC}-\mathrm{GM}^{2}$ 의 평균 패킷 전송 비용을 나타낸다. $\mathrm{GPMIP}$ 의 평균 패킷 전송 비용과 동일하다.

$$
D_{L C G M}=\rho \cdot t_{s u b} \cdot \Phi(N) \cdot(2 \theta+(2 \tau c+b) \eta)
$$

$C_{L C G M}$ 는 $\mathrm{LC}-\mathrm{GM}^{2}$ 의 총 비용을 의미한다.

$$
C_{L C G M}=L_{L C G M}+D_{L C G M}
$$

4.3 수치 분석 결과

이 절에서는 $\mathrm{HMIPv} 6, \mathrm{GPMIP}, \mathrm{LC}-\mathrm{GM}^{2}$ 성능을 분석한다. Table 1은 분석을 위한 기본 매개변수 값을 표시한다. 일부 매개변수 값은[15]에서 참고한다.

Table 1. 분석을 위한 기본 매개변수

\begin{tabular}{|c|c|c|}
\hline $\begin{array}{c}\text { 매개 } \\
\text { 변수 }\end{array}$ & 설명 & 값 \\
\hline$N$ & 도메인 사이즈 & 25 \\
\hline$s$ & 서브넷 영역 & $10 \mathrm{~km} 2$ \\
\hline$v$ & $\mathrm{MN}$ 의 평균이동 속도 & $20 \mathrm{~km} / \mathrm{hr}$ \\
\hline$a$ & 첫번째-두번째 계층의 홉 카운트 & 6 \\
\hline$b$ & 두번째간의 홉 카운트 & 4 \\
\hline$c$ & 두번째-세번째 계층의 홉 카운트 & 2 \\
\hline$d$ & 세번째간의 홉 카운트 & 1 \\
\hline$\varepsilon$ & 특정 도메인 IN/OUT 의 평균 개수 & 2 \\
\hline$\rho$ & 서브넷 MN의평균 패킷 전송 비율 & 100 \\
\hline$\theta$ & 무선 단위 전송 비율 & 2 \\
\hline$\eta$ & 유선 단위 전송 비율 & 1 \\
\hline$\tau$ & 패킷 터널 추가 중량 & 1.2 \\
\hline$q$ & 하나의 패킷이 $\mathrm{MN}$ 에 직접 연결되는 & 0.7 \\
\hline & 비율 & 0.7 \\
\hline
\end{tabular}

Fig. 13는 도메인 내에는 도메인 사이즈가 증가하여도 비 용이 증가하지 않는 결과를 나타낸다. 하지만 도메인 간의 이동은 도메인 사이즈가 증가할 수록 $\mathrm{HMIPv6}$ 와 GPMIP는 비용이 증가를 보인다. 도메인 사이즈가 증가하여도 $\mathrm{LC}-\mathrm{GM}^{2}$ 은 비용의 증가가 없으며, HMIPv6, GPMIP 보다 좋은 성능을 나타낸다. 이 결과로 PMIPv6 기반이 HMIPv6 기반보다 좋은 성능을 의미하며, GPMIP의 $\mathrm{VDB}, \mathrm{GDB}$, $\mathrm{DHCP}$ 서버를 사용하지 않아서 더 좋은 성능 결과를 보여준 다. 또한, Fig. 14는 도메인 사이즈가 증가함에 따라 패킷 전 송 비용의 결과를 표시한다. HMIPv6는 위치 업데이트 비용 이 선행적으로 증가한다. 하지만 PMIPv6 기반의 GPMIP 와 $\mathrm{LC}-\mathrm{GM}^{2}$ 에서는 더 좋은 성능을 보여준다.

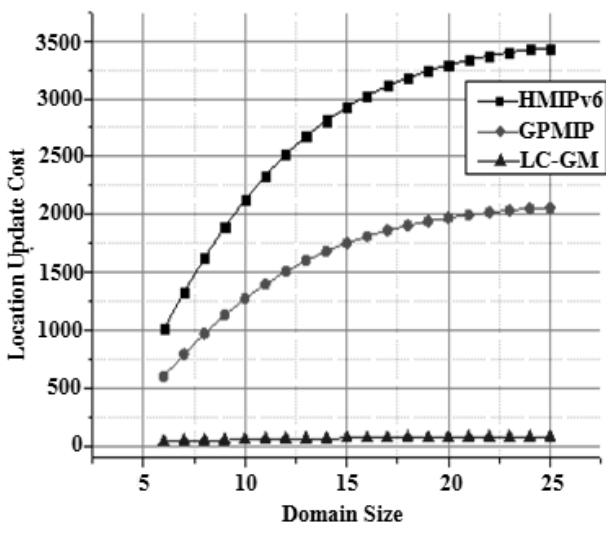

Fig. 13. 도메인 사이즈 vs위치 업데이트 비용 


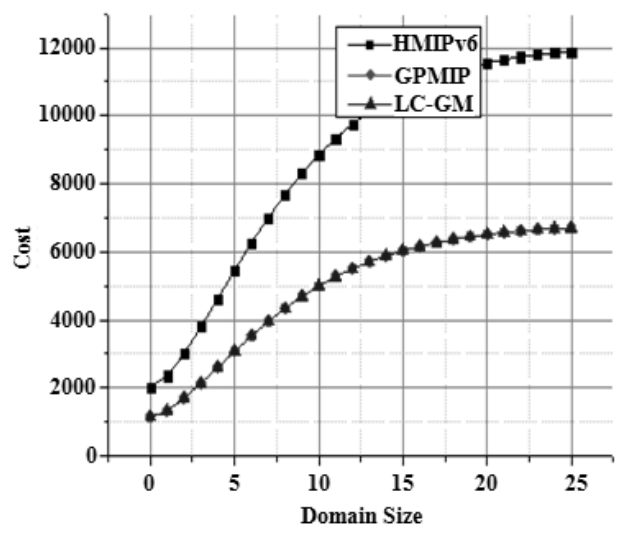

Fig. 14. 도메인 사이즈 vs 패킷 전송 비용

Fig. 15에서는 도메인 사이즈가 증가 할 때 총 비용 결과 값을 표시한다. HMIPv6보다 PMIPv6 기반이 성능이 좋음을 보이며, $\mathrm{LC}-\mathrm{GM}^{2}$ 이 GPMIP 보다 총 비용이 낮다.

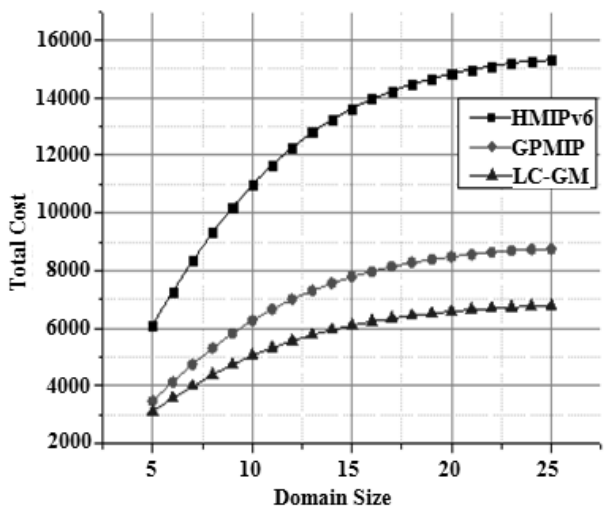

Fig. 15. 도메인 사이즈 vs 총 비용

Fig. 16 에서는 $\mathrm{MN}$ 의 평균이동 속도가 증가하여도 위치 업데이트 비용은 증가하지 않지만 패킷 전송 비용은 감소하 는 것을 나타낸다. HMIPv6 보다는 네트워크 기반의 $\mathrm{PMIPv6}$ 를 기반인 $\mathrm{GPMIP}$ 와 $\mathrm{LC}-\mathrm{GM}^{2}$ 가 더 좋은 성능을 보여준다.

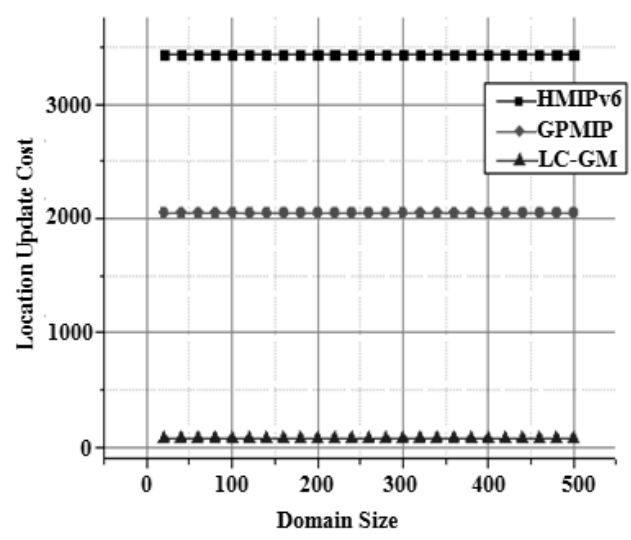

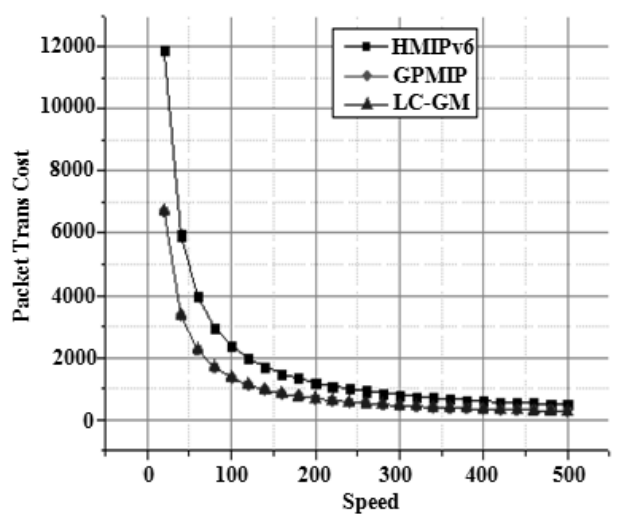

Fig. 16. $\mathrm{MN}$ 의 평균이동 속도 vs 위치 업데이트 비용과 $\mathrm{MN}$ 의 평균이동 속도 VS 패킷 전송 비용

Fig. 17에서는 $\mathrm{MN}$ 의 평균이동 속도가 증가할 때 비용을 나타내며, Fig. 18는 첫번째 계층과 두번째 계층의 홉 카운 트 증가할 때 총 비용을 나타낸다. Fig. 19는 두번째 계층간 에 홉 카운트 증가할 때 총 비용을 나타낸다.

Fig. 20은 두번째 계층과 세번째 계층간의 홉 카운트가 증가할 때 총 비용을 설명한다. $\mathrm{LC}-\mathrm{GM}^{2}$ 도 선형 증가를 하 지만 HMIPv6, GPMIP 총 비용과 많은 차이를 보인다.

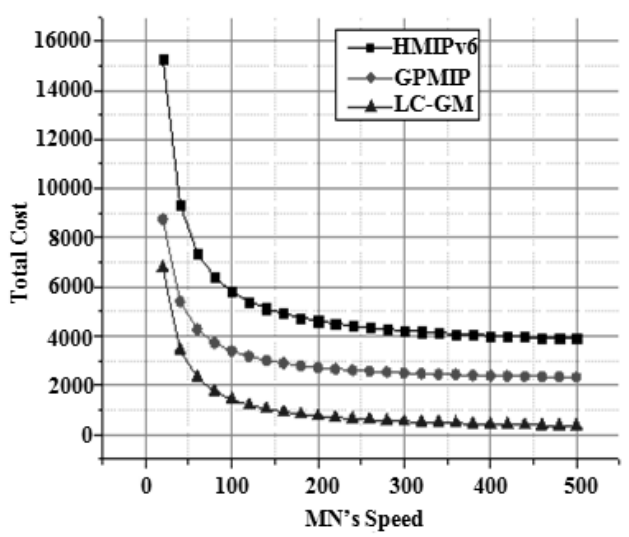

Fig. 17. $\mathrm{MN}$ 의 평균이동 속도 vs 총 전송 비용

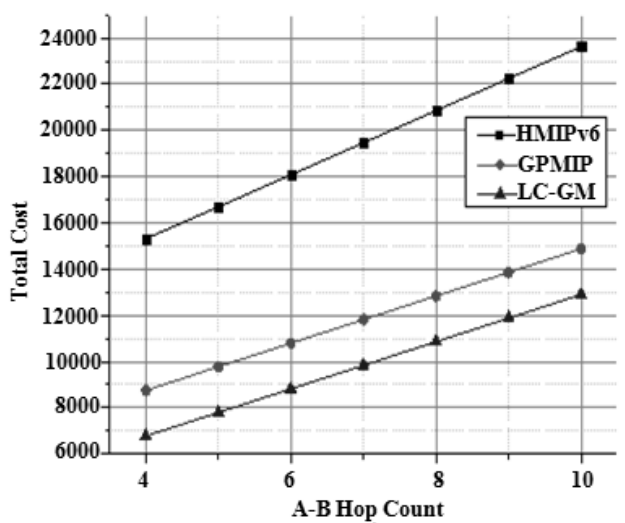

Fig. 18. 첫번째-두번째 계층의 홉 카운트 vs 비용 


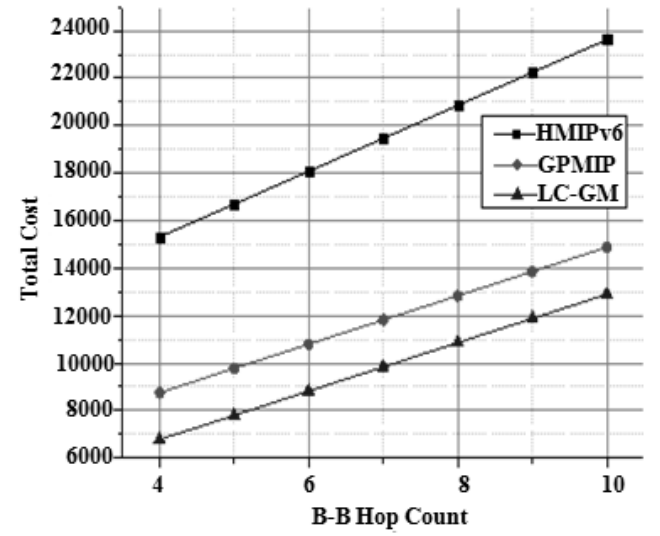

Fig. 19. 두번째 계층간의 홉 카운드 vs 비용
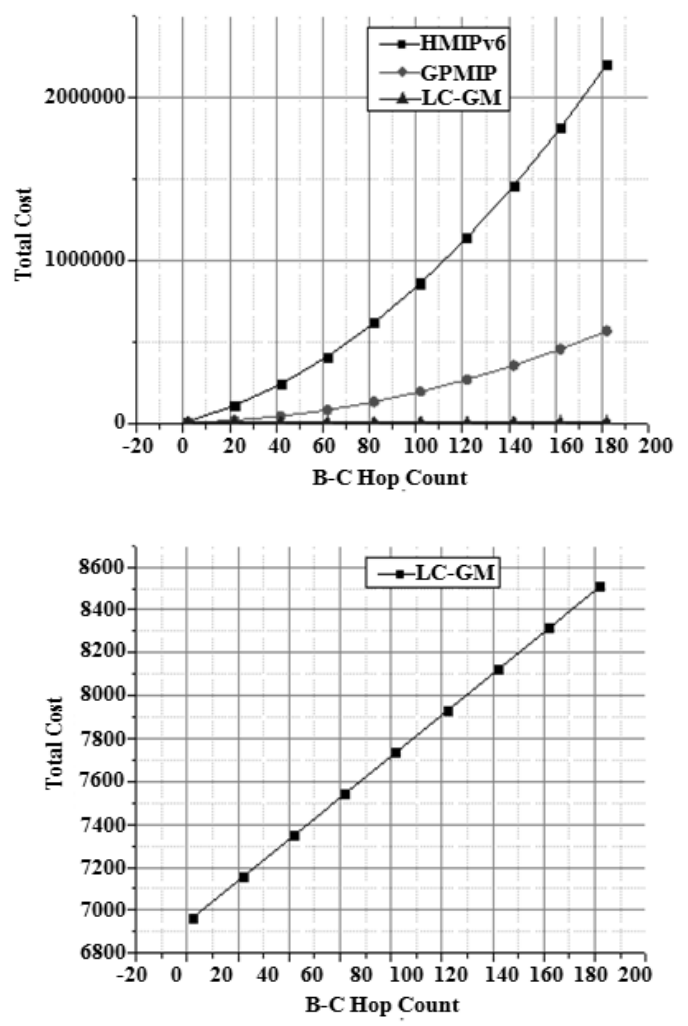

Fig. 20. 두번째-세번째 계층간의 홉 카운드 vs 비용

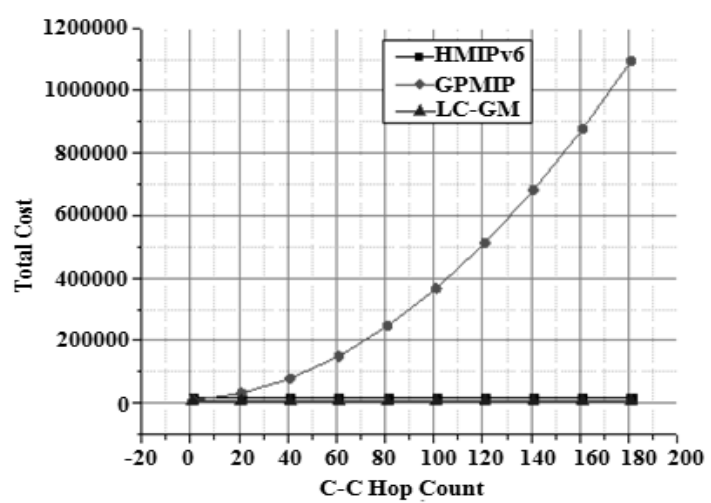

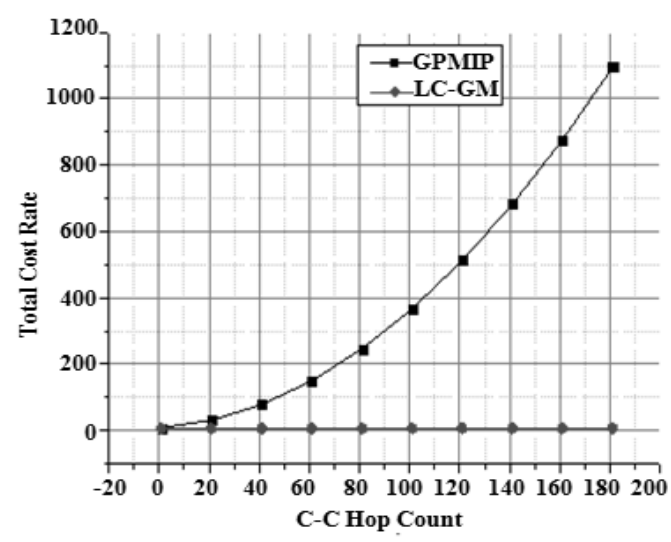

Fig. 21. 세번째 계층간의 홉 카운드 vs 비용

Fig. 21은 세번째 계층간의 홉 카운트가 증가할 때 총 비 용을 설명한다. $\mathrm{LC}-\mathrm{GM}^{2}$ 는 거의 증가하지 않는다.

Fig. 22은 유선 단위 전송 비용이 증가할 때 총 비용을 설명하며, Fig. 23은 무선 단위 전송 비용이 증가할 때 총 비용을 설명한다.

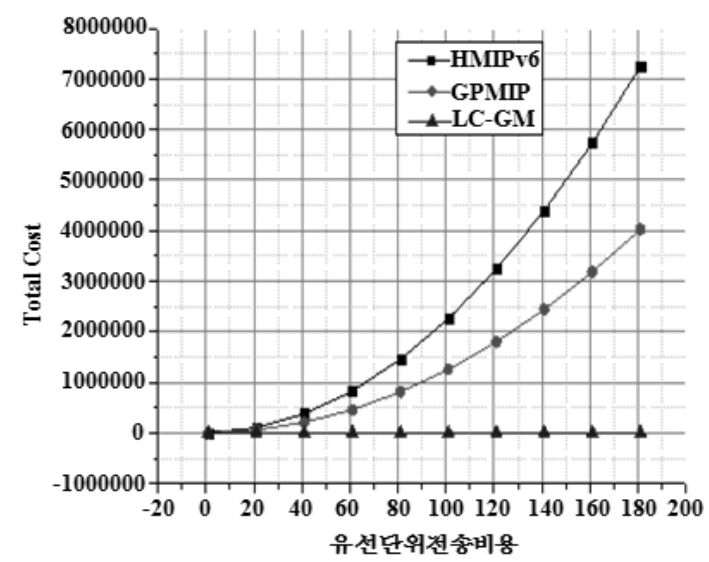

Fig. 22. 유선 단위 전송 비용 vs 비용

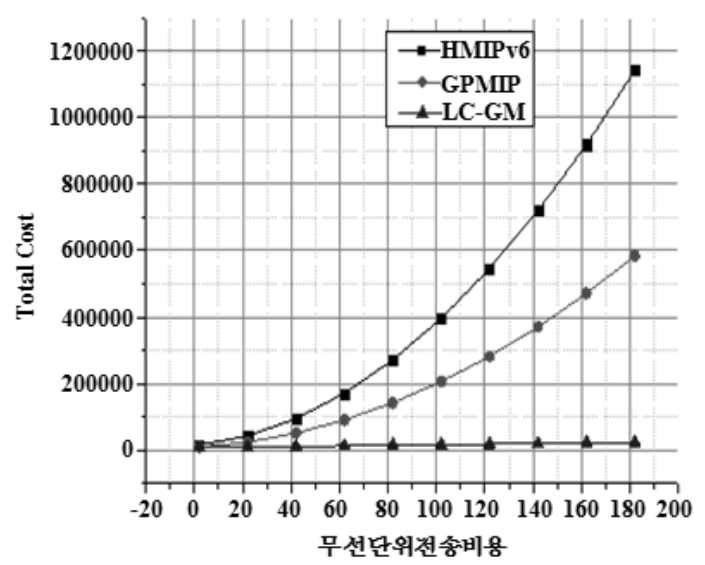

Fig. 23. 무선 단위 전송 비용 vs 비용 


\section{5. 결 론}

본 논문은 새로운 글로벌 이동성관리 아키텍처와 프로 토콜 절차를 제안하였다. 프록시 모바일 IP 기술을 기반으 로 글로벌 이동성관리를 가능하도록 한다. 네트워크 분석 모델과 유체 흐름 이동성 모델로 총 비용을 계산하여 HMIPv6, GPMIP와 제안 기법에 대하여 비교한다. $\mathrm{MN}$ 의 평균 이동 속도, 도메인의 크기 계층간의 홉 카운트 등 다 양한 시스템 매개변수의 영향을 총 비용으로 분석한다. 분 석 결과, 제안된 $\mathrm{LC}-\mathrm{GM}^{2}$ 대한 평균 도메인 체류 시간 동 안 $\mathrm{MN}$ 에 의해 생성되는 총 비용은 HMIPv6, GPMIP보다 낮다는 것을 보여준다. 앞으로 PMIPv6 도메인을 포함하여 $\mathrm{MIPv} 4 / \mathrm{MIPv6}$ 지원으로 확장하여 글로벌 이동성관리에 대하여 연구할 것이다.

\section{참 고 문 헌}

[1] D. Johnson D, Perkins C, and Arkko J, "Mobility support in IPv6," IETF RFC 3775, June, 2004.

[2] Soliman H, Castelluccia C, El Malki K, and Bellier L, "Hierarchical Mobile IPv6 Mobility Management (HMIPv6)," IETF RFC 4140, August, 2005.

[3] Gundavelli S, Leung K, Devarapalli V, Chowdhury K, and Patil B, “Proxy mobile IPv6," IETF RFC 5213, August, 2008.

[4] 20. Patel A, Leung K, Khalil M, Akhtar H, and Chowdhury K , "Mobile node identifier option formobile IPv6 (MIPv6)," IETF RFC 4283, November, 2005.

[5] Droms R, Bound J, Volz B, Lemon T, Perkins C. and Carney M, "Dynamic host configuration protocol for IPv6(DHCPv6)," IETF RFC 3315, November, 2007.

[6] T. Narten, E. Nordmark, and W. Simpson, "Neighbor Discovery for IP Version 6 (IPv6)," IETF RFC 2461, December, 1998.

[7] Sarikaya B, and Xia F, "DHCPv6 based home network Prefix delegation for PMIPv6," IETF draft-sarikaya-netlmmprefix-delegation-01, November, 2007.

[8] Huachun Zhou, Hongke Zhang, Yajuan Qin, Hwang-Cheng Wang and Han-Chieh Chao, "A Proxy Mobile IPv6 Based Global Mobility Management Architecture and Protocol," Mobile Netw Appl 15:530 - 542, July, 2009.

[9] Troan O, Droms R, "IPv6 prefix Options for Dynamic Host Configuration Protocol (DHCP) version 6," IETF RFC 3633.

[10] Lior A, Chowdhury K and Tschofenig H , "RADIUS mobile IPv6 support," IETF draft-ietf-mip6-radius-03, May, 2009.

[11] Vixie P, Thomson S, Rekhter Y, and Bound J, "Dynamic updates in the Domain Name System (DNS UPDATE)," IETF RFC 2136, April, 1997.

[12] Kong K-S, Song MB, Park KJ, and Hwang C-S, "A comparative analysis on the signaling load of mobile IPv6 and hierarchical mobile IPv6: analytical approach," IEICE Trans Information and Systems E89-D(1):139 - 149, January, 2006.

[13] Zhang X, Castellanos G, and Campbell AT "P-MIP: Paging extensions for mobile IP," ACM/Kluwer Mobile Networks and Applications 7(2):127 - 141.

[14] Pack S, and Choi Y, "A study on performance of hierarchical mobile IPv6 in IP-based cellular networks," IEICE Trans Commun E87-B(3):462 - 469, May, 2004.

[15] Kong K, Han Y, Shin M, Yoo H and Lee W, "Mobility management for All-IP mobile networks: mobile IPv6 vs. Proxy mobile IPv6," IEEE Wireless Communications, pp.36-45, April, 2008.

[16] Seamless Wireless Connectivity for Multimedia Services in High Speed Trains Karimi, O.B; Jiangchuan Liu; Chonggang Wang Selected Areas in Communications, IEEE Journal on Volume: 30 , Issue: 4 Digital Object Identifier: 10.1109/ JSAC.2012.120507 Publication Year: 2012, pp.729-739.

[17] A comparative study of WiMAX and LTE as the next generation mobile enterprise network Leo Yi; Kai Miao; Liu, A. Advanced Communication Technology (ICACT), 2011 13th International Conference on Publication Year: 2011, pp.654-658.

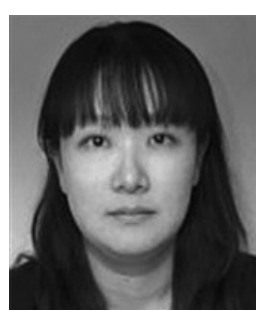

김 종 연

e-mail : search100@naver.com 2009년 현 재 성균관대학교 컴퓨터공학과 석사 관심분야: 모바일 네트워크, 알고리즘

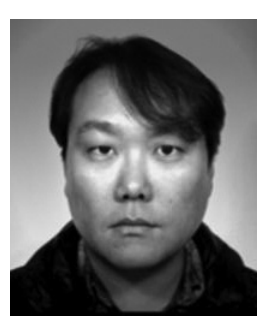
e-mail :holosun@wins21.co.kr 2010년 현 재 성균관대학교 정보통신공학과 석사 관심분야: 모바일 네트워크, 네트워크 보안 


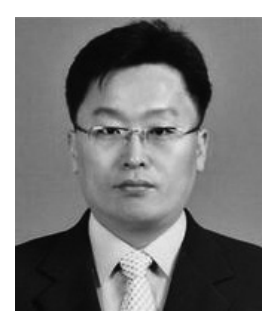

정 종 필

e-mail : jpjeong@skku.edu

2008년 성균관대학교 정보통신대학 (공학박사)

2009년 성균관대학교 컨버전스연구소 연구교수

2010년 현 재 성균관대학교 산학협력단 산학협력중점교수

관심분야: 모바일컴퓨팅, 센서 이동, 차량 모바일 네트워크, 스 마트기기 보안, 네트워크 보안, IT융합, 인테랙션사이 언스 등 